\title{
RETINAL DETACHMENT COMPLICATING SCLERAL-SUTURED POSTERIOR CHAMBER INTRAOCULAR LENS SURGERY
}

\author{
ROBERT D. BOURKE, PETER J. GRAY, PAUL H. ROSEN and ROBERT J. COOLING \\ London
}

\begin{abstract}
SUMMARY
Although retinal detachment has been reported in association with sutured posterior chamber intraocular lenses (PCIOL), detailed analysis of the pathogenesis, clinical features and risk factors is lacking. Thirty-nine patients who had undergone surgery for scleral-sutured PCIOL were therefore reviewed, revealing 8 patients with associated retinal tears or detachments. Retinal breaks resulted from vitreous incarceration by the intraocular suture (6), post-operative vitreous detachment (1), preretinal manipulation of the dislocated PCIOL (1), surgical entry-sites (1) and surgical induction of posterior vitreous detachment (1). An axial length $>\mathbf{2 5} \mathbf{~ m m}$ was associated with the development of retinal tears $(p<0.05$, Fisher's exact test). All patients had attached retina with median visual acuity of $6 / 12$ (range 6/6 to CF) at last follow-up (median 15 months, range 1-41 months). In patients requiring a pars plana approach, careful attention to the posterior hyaloid face, basal gel, surgical entry-sites and suture tract is recommended to reduce the risk of retinal detachment associated with scleral-sutured PCIOL procedures.
\end{abstract}

An accurately positioned posterior chamber intraocular lens (PCIOL) confers optical and anatomical advantages over anterior chamber intraocular lenses (ACIOL), and a lower incidence of complications, including corneal endothelial decompensation, iritis, and glaucoma. ${ }^{1-3}$ Pre-existing ocular pathology may limit the choice of intraocular lens style as capsular support is insufficient in eyes with dislocated lenses and following intracapsular cataract extraction and pars plana lensectomy. ACIOL implantation is inappropriate if the anterior chamber angle is abnormal or iris support is inadequate. To allow

From: Vitreo-Retinal Service, Moorfields Eye Hospital, City Road, London, UK.

Correspondence to: Robert D. Bourke, FRACO, FRACS, Royal Brisbane Hospital, Brisbane 4029, Australia.
PCIOL implantation in such eyes, Girard ${ }^{4}$ described a pars-plana-fixated PCIOL technique in 1981. Ciliary sulcus fixation was later introduced ${ }^{5-14}$ with additional surgical techniques for the management of posteriorly dislocated PCIOLs. ${ }^{15-22}$

Scleral-sutured PCIOL techniques carry a number of inherent risk factors for retinal detachment. These relate to pre-existing pathology such as aphakia, trauma, myopia and vitreous loss, in addition to the risks associated with transscleral suturing, manipulation of the intraocular lens, vitreous disturbance, pars plana entry-sites and repeated entry of pars plana instruments.

Not unexpectedly, retinal detachment secondary to scleral-sutured PCIOL surgery has been described in a number of reports, ${ }^{4,23-26}$ although none detail the pathogenesis, clinical characteristics and outcome of this significant complication. We therefore retrospectively reviewed a series of patients with scleralsutured PCIOLs to identify the risk factors, clinical features and outcomes associated with the development of retinal breaks or detachment.

\section{PATIENTS AND METHODS}

Retrospective analysis of 39 patients with scleralsutured PCIOLs, identified 8 patients with secondary retinal tears or detachment. Thirty-seven patients had scleral-sutured PCIOL surgery performed at one hospital, 2 patients were referred with retinal detachment following sutured-lens surgery at other institutions, and 31 of 39 patients (79\%) originated from a tertiary referral ocular trauma and vitreoretinal clinic. The pre-operative, intraoperative and post-operative clinical findings in 8 patients who developed retinal tears were compared with the uncomplicated group of 31 patients. In patients undergoing pars plana vitrectomy procedures, particular attention was paid to the intraoperative vitreoretinal relationships such as the presence of a 
posterior vitreous detachment (defined by the presence of a Weiss' ring, or the absence of a posterior hyaloid face in previously vitrectomised eyes), the site and nature of the retinal breaks, and the presence of vitreous incarceration to the suture tract or instrument entry ports. In such patients, observations regarding anterior vitreoretinal relations were made employing an operating microscope at high magnification whilst simultaneously performing scleral indentation and endoillumination. Statistical analyses employed Fisher's exact test for comparison of proportions, and the Wilcoxon rank sum test for the non-parametric comparison of the medians of unpaired samples.

\section{CASE REPORTS}

Seven of 8 patients with retinal tears or retinal detachments associated with sutured PCIOL procedures are described (Table I, Fig. 1).

\section{Retinal Detachment Cases}

Five patients developed retinal detachment following scleral-sutured PCIOL procedures.

\section{Patient 1}

A 70-year-old myopic woman presented with a retinal detachment in the right eye 6 weeks after scleral fixation of a posteriorly dislocated PCIOL. Scleral fixation PCIOL surgery comprised pars plana vitrectomy (PPV), dislocated PCIOL removal, and suturing of a replacement PCIOL to the ciliary sulcus using a curved Eguchi needle with $10-0$ polypropylene suture, introduced via a corneal section (Eguchi PC9, 1/4 circle, spatulated needle with 10-0 monofilament polypropylene suture, Alcon 307901).
Six weeks later, the patient presented with a total retinal detachment. Three retinal breaks were identified, caused by three different pathogenetic mechanisms. A small posterior tear was identified related to retinal trauma incurred during the removal of the pre-retinal PCIOL. A vitreous strand was attached to the 4 o'clock retina tear and incarcerated with the upper nasal suture, and an additional small tear was noted in relation to the superotemporal pars plana entry-site. Posterior vitreous detachment (PVD) was confirmed at PPV, and 'complete' excision of the vitreous base and incarcerated gel was performed. Fluid-air exchange via the posterior retinal break, laser treatment, encirclement and $\mathrm{SF}_{6}$ gas exchange resulted in temporary retinal reattachment. Proliferative vitreoretinopathy ensued, requiring epiretinal dissection, silicone oil exchange and further endolaser treatment. At 2-year follow-up visual acuity is $3 / 60$ with attached posterior retina and a stable inferior traction retinal detachment, in the presence of intraocular silicone oil.

\section{Patient 2}

A 68-year-old myopic man presented with a left superior nasal retinal detachment 6 weeks after scleral-sutured PCIOL surgery for a posteriorly dislocated PCIOL. Twelve months previously he had undergone successful scleral buckling for retinal detachment in this eye.

Scleral-sutured PCIOL surgery included PPV, with removal of the posterior hyaloid face and vitreous base clearance aided by scleral indentation. Perfluoro-n-octane flotation of the PCIOL stabilised the dislocated PCIOL behind the iris plane whilst the optic holes were threaded with 10-0 polypropylene

Table I. Clinical histories and surgical synopses of the eight patients with retinal tears with and without retinal detachment, complicating scleral sutured PCIOL surgery

\begin{tabular}{|c|c|c|c|c|c|c|c|}
\hline $\begin{array}{l}\text { Patient } \\
\text { no. }\end{array}$ & Indication & $\begin{array}{l}\text { Axial length } \\
(\mathrm{mm})\end{array}$ & $\begin{array}{l}\text { Vitreous } \\
\text { surgery }^{\mathrm{a}}\end{array}$ & $\begin{array}{l}\text { SSPCIOL } \\
\text { technique }\end{array}$ & $\begin{array}{c}\text { Retinal } \\
\text { sequelae }\end{array}$ & $\begin{array}{l}\text { Interval to } \\
\text { RD or tear }\end{array}$ & $\begin{array}{c}\text { Visual } \\
\text { outcome }\end{array}$ \\
\hline 1 & Dis PCIOL & 25.10 & PPV & IOLX Eguchi & $\begin{array}{l}\text { RD, multiple breaks } \\
\text { (Fig. 1) }\end{array}$ & 6 weeks & $3 / 60$ \\
\hline 2 & Dis PCIOL & 25.30 & PPV & Modified Lewis & $\begin{array}{l}\text { RD, suture related } \\
\text { (Fig. 1) }\end{array}$ & 6 weeks & $6 / 9$ \\
\hline 3 & Aphakia & 25.90 & None & Lewis & $\begin{array}{l}\text { RD, suture related } \\
\text { (Fig. 1) }\end{array}$ & 8 weeks & $6 / 18$ \\
\hline 4 & $\begin{array}{l}\text { Traumatic dis cataract } \\
\text { and glaucoma }\end{array}$ & 24.47 & VL & Eguchi & $\begin{array}{l}\text { RD, suture related } \\
\text { (Fig. 1) }\end{array}$ & 6.5 weeks & $6 / 9$ \\
\hline 5 & Dis PCIOL & 25.10 & $\begin{array}{l}\text { None but received } \\
\text { intravitreal antibiotics } \\
\text { for endophthalmitis }\end{array}$ & Not known & $\begin{array}{l}\text { RD, post-op PVD } \\
\text { (Fig. 2) }\end{array}$ & 18 weeks & $\mathrm{CF}$ \\
\hline 6 & Dis PCIOL & 23.45 & PPV & IOLX Eguchi & $\begin{array}{l}\text { Retinal tear, suture } \\
\text { related (Fig. 2) }\end{array}$ & $\begin{array}{l}\text { Peroperative } \\
\text { finding }\end{array}$ & $6 / 9$ \\
\hline 7 & Aphakia & 27.3 & PPV & Lewis & $\begin{array}{l}\text { Retinal tear at PVD } \\
\text { induction (Fig. 2) }\end{array}$ & $\begin{array}{l}\text { Peroperative } \\
\text { finding }\end{array}$ & $6 / 6$ \\
\hline $8^{\mathrm{b}}$ & Dis PCIOL & 24.06 & None & IOLX Lewis & $\begin{array}{l}\text { Retinal tear, suture } \\
\text { related (Fig. 2) }\end{array}$ & 4 weeks & $6 / 60$ \\
\hline
\end{tabular}

PCIOL, posterior chamber intraocular lens; SSPCIOL, scleral-sutured posterior chamber intraocular lens; PPV, pars plana vitrectomy; VL, pars plana vitreolensectomy; IOLX, intraocular lens explantation and exchange; RD, retinal detachment; dis, dislocated or subluxated.

${ }^{a}$ Vitreous surgery at the time of SSPCIOL surgery.

b Suffered a fatal myocardial infarction prior to treatment for retinal tear. 

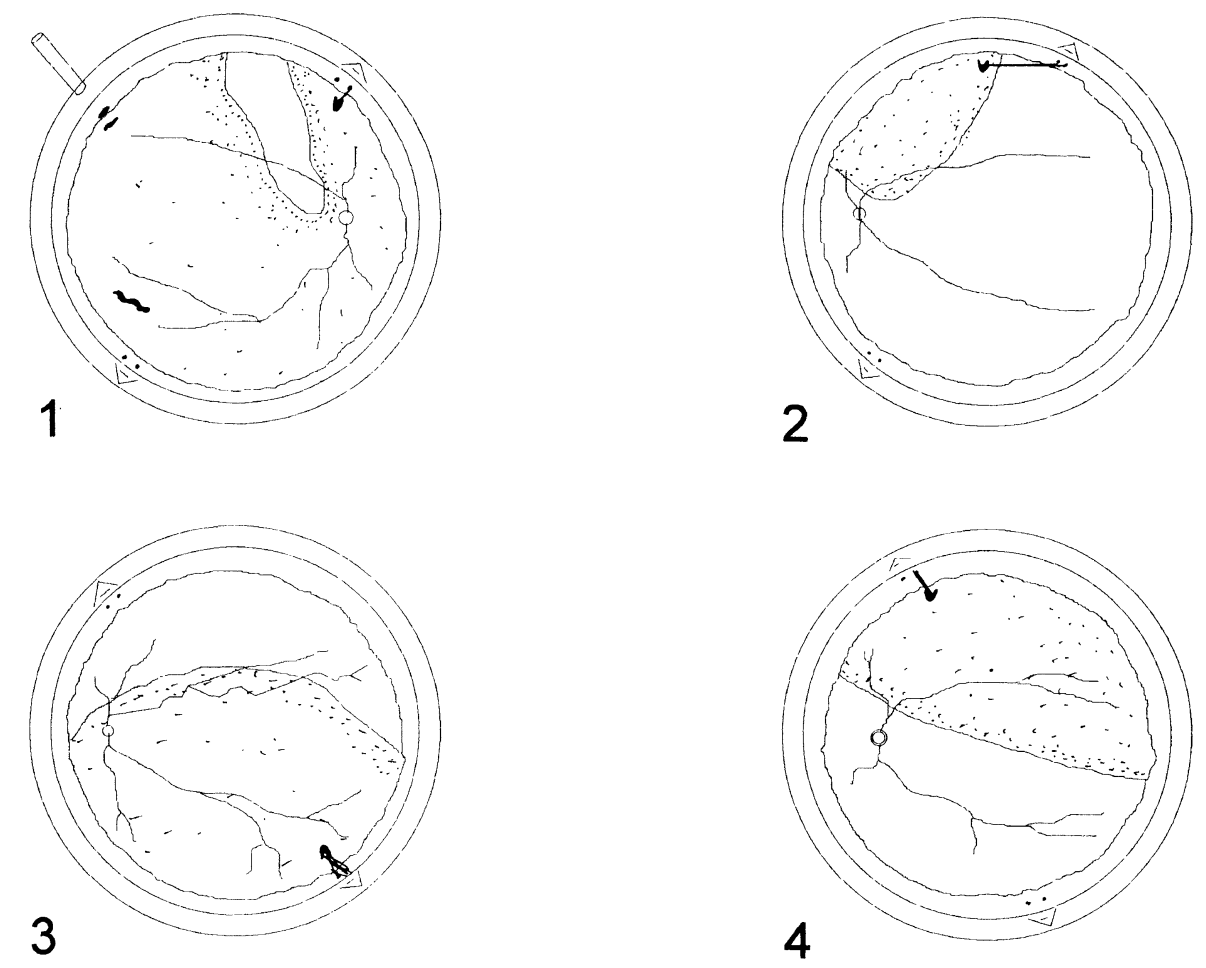

Fig. 1. Schematic representation of the location and orientation of the retinal breaks in patients 1 to 4 and of their relationship to the suture sites of the scleral-sutured posterior chamber intraocular lens.

using intraocular forceps. The sutures were tied to sclera under flaps at 1 o'clock and 7 o'clock.

Six weeks later he presented with a left superior nasal retinal detachment resulting from a small traction tear adjacent to an area of cryopexy. The tear, situated at 11 o'clock, was elevated by a fine strand of vitreous attached to the suture at 1 o'clock. Pneumatic retinopexy with $\mathrm{C}_{3} \mathrm{~F}_{8}$ gas and subsequent indirect laser photocoagulation was performed. Eight weeks later the nasal retina redetached with subretinal fluid tracking from 12 o'clock. The initial break was closed with evidence of adequate laser reaction, although an additional break could not be identified amongst the pigmentary changes within previous cryo-treated retina. Pneumatic retinopexy with $\mathrm{C}_{3} \mathrm{~F}_{8}$ gas and broad indirect laser demarcation to the superior retinal periphery was performed. The retina was attached, with visual acuity of $6 / 96$ months later.

\section{Patient 3}

A 73-year-old myopic woman was referred with a left retinal detachment 8 weeks after left scleral-sutured PCIOL surgery for aphakia following previous intracapsular cataract extraction. Despite the preoperative finding of vitreous herniation into the anterior chamber, the referring surgeon elected not to perform an anterior vitrectomy during the sutured PCIOL surgery. Although the Lewis technique ${ }^{6}$ was attempted, resistance to the transscleral passage of the straight polypropylene-threaded needle was overcome by gripping the needle with vitreous forceps introduced via the ciliary sulcus.

Eight weeks later, the patient was referred with a left inferior retinal detachment, secondary to a postoral traction tear tethered by vitreous inserted into the 5 o'clock suture site. This was treated with cryotherapy, sub-retinal fluid drainage and scleral buckling. Proliferative vitreoretinopathy developed, with reopening of the break, and PPV with epiretinal membrane peeling, silicone oil tamponade and endolaser treatment was performed. Thirteen months later, the retina remains attached with visual acuity of 6/18. Silicone oil remains in situ and topical betaxolol is required for intraocular pressure control.

\section{Patient 4}

A 50-year-old man presented with a right retinal detachment 45 days after pars plana vitreolensectomy, scleral-sutured PCIOL and trabeculectomy for a traumatic subluxed cataractous lens and open angle glaucoma. During vitrectomy a 10-0 polypropylene suture was tied to the PCIOL haptics, and a curved Eguchi needle passed internally through the corneal section to exit via ciliary sulcus. The lens was then inserted and sutures were tied under scleral flaps at 11 and 5 o'clock. An operculated superotemporal entry-site break was noted during surgery and treated with cryoretinopexy and $\mathrm{C}_{3} \mathrm{~F}_{8}$. The early 

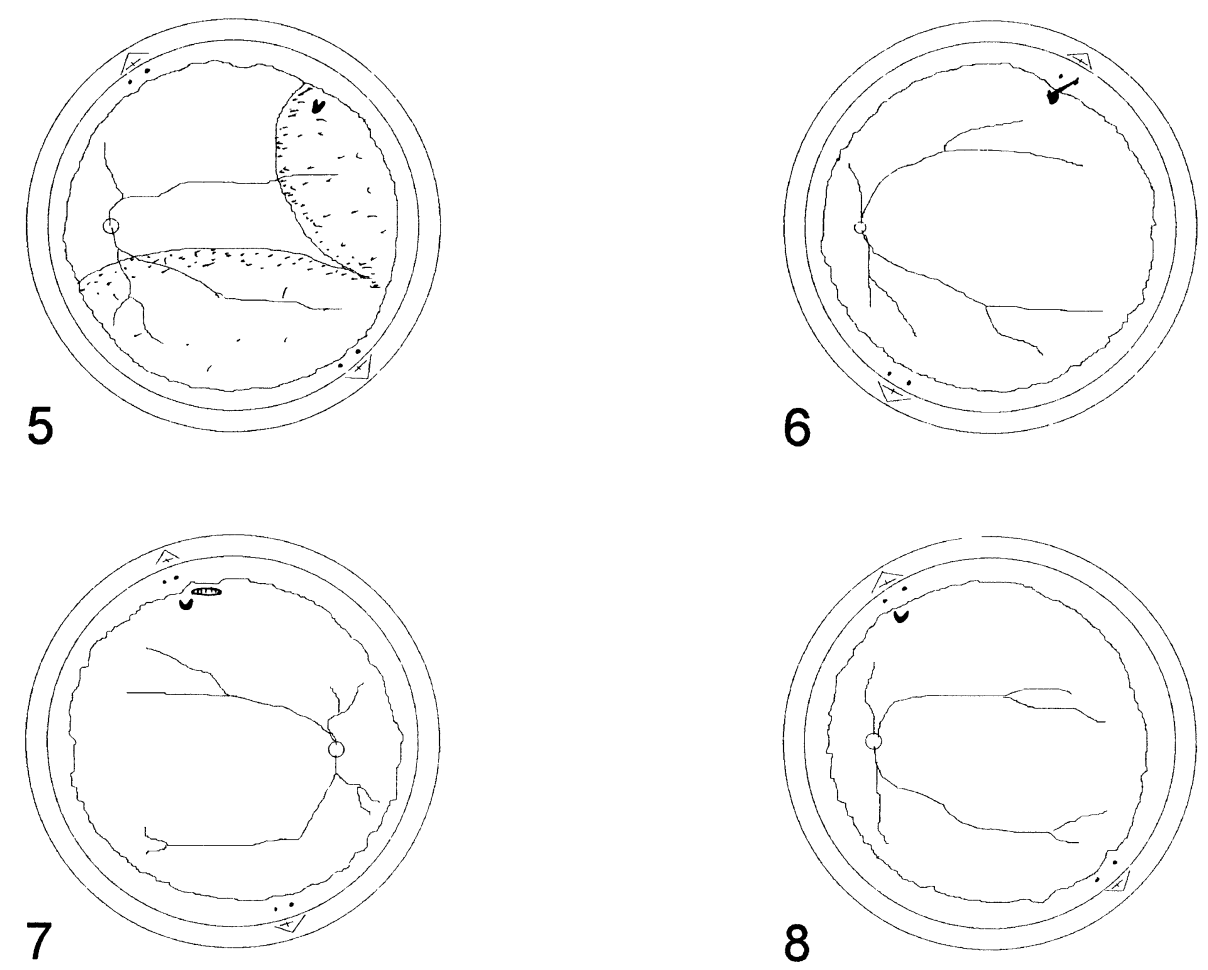

Fig. 2. Schematic representation of the location and orientation of the retinal breaks in patients 5 to 8 and of their relationship to the suture sites of the scleral-sutured posterior chamber intraocular lens.

post-operative period was complicated by choroidal effusions, which resorbed by 6 weeks.

The patient presented $6 \frac{1}{2}$ weeks after surgery with a retinal detachment related to a second small postoral tear elevated by vitreous attached to the 12 o'clock suture. PPV with excision of vitreous around the superior suture, fluid-air exchange via the 12 o'clock break, endolaser treatment, and $\mathrm{SF}_{6}$ gas exchange were performed. Twenty-three months later visual acuity is $6 / 9$ and the retina is attached in all areas.

\section{Patient 5}

An 83-year-old myopic woman was referred to the Vitreo-retinal Service with a left retinal detachment 18 weeks after scleral-sutured PCIOL surgery for a subluxed PCIOL. She had undergone anterior vitrectomy and a Lewis technique ${ }^{6}$ scleral-suture PCIOL procedure but 5 days later developed culture-negative endophthalmitis which responded to intravitreal antibiotics.

Four months later she was referred with an inferior bullous retinal detachment involving the macula. She underwent PPV and a small operculated break was identified at 2 o'clock in the presence of a PVD. The suture sites (11 and 5 o'clock) were not associated with the break. Four months later the retina is attached, but corneal oedema persists, limiting visual acuity to counting fingers.

\section{Retinal Tears}

Two patients were noted to have retinal tears during scleral-sutured PCIOL procedures (Table I, Fig. 2).

\section{Patient 6}

An 81-year-old woman underwent PPV, including removal of a dislocated PCIOL followed by suturing of an exchanged PCIOL into the ciliary sulcus using a 10-0 polypropylene suture on a curved Eguchi needle. The peripheral retina was inspected prior to closure, and a U-tear in lattice degeneration was noted at 2 o'clock with a vitreous strand bridging the U-tear and the suture. Intraoperative cryoretinopexy and intraocular air were successful in closing the break. Fourteen months later, the retina is attached and visual acuity is $6 / 9$.

\section{Patient 7}

A 31-year-old myopic man with a history of Fuch's heterochromic cyclitis and previous lensectomy underwent PPV and scleral-sutured PCIOL for aphakia, vitreous floaters and contact lens intolerance. PVD was induced by passive aspiration, during which a retinal tear developed at the posterior edge of a peripheral pigmented chorioretinal scar. The basal gel was cleared and a sutured PCIOL inserted using the Lewis technique. The tear was treated with cryotherapy and $\mathrm{SF}_{6}$ internal tamponade. Five months later the vision is $6 / 6$, with attached retina. 
Table II. Clinical histories and surgical synopses of the 31 patients without retinal tears after scleral-sutured PCIOL surgery

\begin{tabular}{|c|c|c|c|c|c|}
\hline $\begin{array}{l}\text { Patient } \\
\text { no. }\end{array}$ & Indication & $\begin{array}{l}\text { Axial length } \\
(\mathrm{mm})\end{array}$ & $\begin{array}{l}\text { Vitreous } \\
\text { surgery }^{\mathrm{a}}\end{array}$ & $\begin{array}{l}\text { SSPCIOL } \\
\text { technique }\end{array}$ & $\begin{array}{c}\text { Visual } \\
\text { outcome }\end{array}$ \\
\hline 9 & Aphakia & 26.20 & PPV & Eguchi & $6 / 18$ \\
\hline 10 & Aphakia & 23.05 & PPV & Lewis & $6 / 9$ \\
\hline 11 & Aphakia & 23.30 & None & Eguchi & $6 / 12$ \\
\hline 12 & Aphakia & 22.52 & PPV & Lewis & $6 / 9$ \\
\hline 13 & Aphakia & 24.06 & PPV & Lewis & $6 / 6$ \\
\hline 14 & Aphakia & 21.94 & Ant vit & Endosc & $6 / 18$ \\
\hline 15 & Aphakia & 25.37 & PPV & Eguchi & $6 / 9$ \\
\hline 16 & Aphakia & 21.33 & PPV & Lewis & $6 / 9$ \\
\hline 17 & Aphakia & 23.48 & PPV & Endosc & $6 / 9$ \\
\hline 18 & Aphakia & 23.30 & PPV & Lewis & $6 / 12$ \\
\hline 19 & Aphakia & 22.80 & PPV & Eguchi & $6 / 18$ \\
\hline 20 & Aphakia & 22.20 & VL & Endosc & $6 / 18$ \\
\hline 21 & Aphakia & 23.80 & Ant vit & Eguchi & $6 / 6$ \\
\hline 22 & Dis PCIOL & 22.47 & PPV & IOLX Lewis & $6 / 9$ \\
\hline 23 & Aphakia & 23.10 & Ant vit & Lewis & $6 / 12$ \\
\hline 24 & Aphakia & 24.50 & Ant vit & Eguchi & $6 / 24$ \\
\hline 25 & Dis PCIOL & 23.96 & PPV & Snare & $6 / 5$ \\
\hline 26 & Aphakia & 22.69 & PPV & Lewis & $6 / 18$ \\
\hline 27 & Dis PCIOL & 27.90 & PPV & IOLX Lewis & 6.24 \\
\hline 28 & Dis cataract & 23.43 & VL & Lewis & $6 / 6$ \\
\hline 29 & Dis cataract & 21.60 & VL & Eguchi & $6 / 18$ \\
\hline 30 & Dis PCIOL & 23.65 & PPV & Eguchi & $6 / 24$ \\
\hline 31 & Dis PCIOL & 24.00 & PPV & Snare & $6 / 12$ \\
\hline 32 & Dis PCIOL & 24.70 & PPV & Eguchi & $6 / 24$ \\
\hline 33 & Dis PCIOL & 24.33 & PPV & IOLX Lewis & $6 / 24$ \\
\hline 34 & Aphakia & 22.60 & Ant vit & Eguchi & $6 / 12$ \\
\hline 35 & Dis cataract & 24.93 & VL & Lewis & $6 / 9$ \\
\hline 36 & Aphakia & 23.00 & None & Lewis & $6 / 9$ \\
\hline 37 & Aphakia & 24.30 & PPV & Lewis & $6 / 12$ \\
\hline 38 & Dis cataract & 23.78 & VL & Lewis & $6 / 24$ \\
\hline 39 & Aphakia & 23.12 & None & Lewis & $6 / 12$ \\
\hline
\end{tabular}

PCIOL, posterior chamber intraocular lens; SSPCIOL, scleral-sutured posterior chamber intraocular lens; PPV, pars plana vitrectomy; ant vit, anterior vitrectomy; VL, pars plana vitreolensectomy; IOLX, intraocular lens explantation and exchange; RD, retinal detachment; dis, dislocated or subluxated; endosc, under endoscopic control.

${ }^{\mathrm{a}}$ Vitreous surgery at the time of SSPCIOL surgery.

\section{RESULTS}

Of 39 patients with scleral-fixated PCIOLs, 5 developed retinal detachment 3-18 weeks (median 6.4 weeks) following sutured-lens surgery, 2 developed intraoperative retinal breaks treated successfully at the time of scleral-sutured PCIOL, and 1 patient had a retinal tear noted 4 weeks postoperatively (Table I). The overall incidence of retinal detachment following sutured PCIOL procedures performed at one institution was $8 \%(3 / 37)$.

Retinal tears were multiple in 3 of the 8 cases. Retinal tears were related to vitreous incarceration by the intraocular suture (6), aphakia and dynamic vitreous traction (1), retinal damage from manipulation of the dislocated PCIOL (1), vitrectomy entrysites (1) and surgically induced posterior vitreous detachment (1).

Axial lengths were significantly greater in the complicated group (median $25.10 \mathrm{~mm}$, range $23.45-27.30 \mathrm{~mm}$ ) than in the uncomplicated group (median $23.43 \mathrm{~mm}$, range 21.33-27.90 $\mathrm{mm}, p<0.005$, Wilcoxon rank sum) (Tables I, II).

Indications for scleral-sutured PCIOL surgery were dislocated PCIOL (12), traumatic subluxed cataract (5) and aphakia (22). Of the three categories, a higher proportion of eyes undergoing scleral-sutured PCIOL surgery for dislocated lens (PCIOL or cystalline) were represented in the group developing retinal tears $(75 \%, 6 / 8)$ and, conversely, a higher proportion of eyes with pre-operative aphakia were present in the uncomplicated group $(65 \%, 20 /$ $31)$. This failed to reach statistical significance $(p=$ 0.059, Fisher's exact test).

The choice of anterior vitrectomy (8), pars plana vitrectomy (23) or no vitrectomy (5) at the time of scleral-sutured surgery, and the choice of a straight or curved needle for transscleral suture fixation, was not associated with the development of retinal tears ( $p=0.49, p=1.00$, Fisher's exact test). The removal and replacement of a pre-existing posteriorly dislocated PCIOL was performed in $37.5 \%$ (3/8) of eyes developing retinal tears or detachment but in only $9.7 \%(3 / 31)$ of eyes developing no such complications, although this did not achieve statistical significance $(p=0.09$, Fisher's exact test). Other factors, such as the effect of using intraocular introducers to avoid vitreous or retinal impact with posteriorly directed intraocular needles or the preoperative presence of a posterior vitreous detachment, could not be statistically analysed due to incomplete data entry in the uncomplicated group.

The demographic characteristics of the two groups 
were similar, with median age 70 years (range 31-85 years) and 67 years (range 32-90 years), male: female distribution $55: 45$ and $60: 40$, and racial distribution $100 \%$ and $85 \%$ Caucasian, respectively, for the complicated and uncomplicated group $(p=$ 0.36 , Wilcoxon rank sum; $p=1.0, p=1.0$, Fisher's exact test). Median follow-up was 15 months (mean 17.3 months, range $1-41$ months).

All patients developing retinal tears have attached posterior retina with a median visual acuity of $6 / 12$ (range $6 / 6$ to $\mathrm{CF}$ ), compared with $6 / 12$ (range 6/6 to $6 / 24)$ in the uncomplicated group $(p=0.40$, Wilcoxon rank sum). Although the median visual acuity is similar between the two groups, significantly more patients with retinal detachment or tears had vision less than $6 / 60$ ( $p=0.04$, Fisher's exact test).

\section{DISCUSSION}

The pathogenesis of retinal breaks in sutured PCIOL procedures is multifactorial, and multiple breaks due to various mechanisms may exist in a single eye (e.g. patient 1). Factors responsible for retinal tears complicating scleral-sutured PCIOL procedures (as determined by pre-operative biomicroscopy and/or intraoperative observations employing an operating microscope, scleral indentation and endoillumination) were vitreous incarceration by the intraocular suture (6), pars plana entry-sites (1), spontaneous (1) or intraoperative induction of PVD (1), or preretinal IOL manipulations (1).

Suture-related tears occurred within 2 clock-hours of the suture, with fine strands of basal gel tracking from the break towards the suture. Vitreous strands, which were often more obvious at internal retinal examination during vitrectomy, presumably were incarcerated at the time of intraocular needle passage during the original scleral-sutured PCIOL surgery, leading to peroperative tears (e.g. patient 6), or secondary static traction (e.g. patient 2). No retinal breaks were attributable to direct needle perforation of retina, highlighting the fact that care is usually taken to avoid retinal damage by the needle.

Two entry-site tears were recognised and successfully treated intraoperatively with cryo- or laserretinopexy and intraocular fluid-gas exchange. Such peripheral retinal tears are a recognised complication of pars plana instrumentation, occurring in $2 \%{ }^{27}$ to $8 \%{ }^{28}$ of PPV cases. However, a PPV approach is necessary in eyes with posteriorly dislocated IOLs, where entry to the posterior segment is required. Although the risk of retinal breaks is higher in cases requiring a PPV, careful inspection of entry-sites can decrease the risk of retinal detachment, as illustrated by the successful outcome in the two cases mentioned. Intraoperative and post-operative PVD were identified as causative factors in the development of retinal tears in patients 7 and 5 respectively. In general, retinal tears are caused by vitreoretinal traction occurring as a result of PVD. ${ }^{29}$ Central ('core') vitrectomy almost inevitably leads to postoperative PVD and subsequent dynamic vitreoretinal traction, when retinal breaks, including giant retinal tears, can occur. ${ }^{30}$ Although it is beyond the scope of this study to prove this, it could be argued that the surgical induction of a PVD during PPV should allow the intraoperative identification and treatment of retinal breaks that might otherwise occur during delayed post-operative PVD. Indeed, the satisfactory anatomical and visual results in patients with retinal tears recognised intraoperatively might support this approach.

Although most retinal breaks in this series were related to anterior vitreous pathology, posterior retinal breaks can occur. Instrument- or PCIOLretinal touch, incurred whilst snaring preretinal posteriorly dislocated PCIOLs, can result in retinal haemorrhages or retinal breaks leading to retinal detachment. The use of perfluorocarbon heavy liquids (PFCL) to float the PCIOL away from the retina obviates the need for such preretinal IOL manipulation. If recognised intraoperatively, retinal tears should be treated with laser photocoagulation and gas tamponade. In such circumstances, a PVD is essential to avoid post-operative surface traction.

The incidence of retinal detachment in this series was $8 \%$ following sutured PCIOL procedures. Scleral-sutured PCIOL series have reported a retinal detachment incidence of $0.9 \%$ ( 2 cases) ${ }^{26} 2.3 \%$ (3 cases), ${ }^{23} 2.4$ ( 2 cases $)^{24}$ and $3.1 \%$ (1 case), ${ }^{25}$ and other reports ascribe retinal detachment rates of $0.8 \%$ following uncomplicated extracapsular cataract extraction PCIOL surgery, ${ }^{31} 0.85 \%$ for secondary anterior chamber IOLs, ${ }^{32}$ and $5.1 \%$ for intraocular lens exchange procedures. ${ }^{33}$ Pre-existing ocular pathology would be expected to influence the complication rate, and a high retinal detachment incidence in this series may relate to a biased referral pattern. The indication for sutured-PCIOL surgery in most reported series was aphakia unaccompanied by such posterior segment complications as posteriorly dislocated cataract or PCIOLs. ${ }^{7,8,11.13,14,23-25}$ By contrast, $31(79 \%)$ patients in this series were collected from a tertiary referral vitreoretinal service and $17(44 \%)$ patients had pre-operative dislocated lenses (PCIOLs and crystalline). Furthermore, the pre-operative presence of dislocated lenses added further complexity to the required surgery, and the higher incidence of complications in this subgroup may have contributed to a higher complication rate than seen with aphakia.

It may seem paradoxical that 'simple' aphakia, which is a recognised risk factor for retinal detachment in other circumstances, ${ }^{34}$ is not an overriding retinal detachment risk factor in this series. This may 
be explained by the more complex operative manipulations required in the other eyes with dislocated lenses in this series (as opposed to 'simple aphakia'), such as multiple pars plana entry, ultrasonic fragmentation, preretinal manipulations and possible removal of the PCIOL, with attendant risks of vitreous base disturbance and direct retinal trauma. In addition, aphakia is associated with a higher incidence of $\mathrm{PVD}^{29}$ and such eyes not developing retinal tears at the time of posterior vitreous detachment are probably at a lower risk of developing subsequent tears than are eyes with attached posterior vitreous. ${ }^{35}$ Although it might be hypothesised that aphakic patients who have a preexisting PVD and no retinal detachment are therefore at a decreased risk of retinal detachment following scleral-sutured PCIOL surgery, incomplete data (regarding the pre-operative presence of a PVD in the uncomplicated group) prevented statistical analysis of the presumed protective role of a preexisting PVD.

Axial myopia is a recognised predisposing factor for retinal detachment in general ${ }^{36}$ and an axial length $>25 \mathrm{~mm}$ is associated with retinal detachment following routine extracapsular cataract surgery. ${ }^{37}$ Our study confirms a similar association between the development of retinal tears or detachment following sçleral-sutured PCIOL and an axial length $>25 \mathrm{~mm}$ $(p<0.005$, Fisher's exact test). Other factors such as race, age and sex were not significantly associated with the development of retinal breaks, although a larger series would be required to exclude such associations.

There was a wide range in the interval from scleral-sutured PCIOL surgery to the development of retinal detachment (6-17.7 weeks). Subretinal fluid recruitment rate is related to the size of the retinal break and the vitreous status, and therefore a vitrectomised eye will recruit fluid more rapidly than an eye with residual attached gel. ${ }^{38}$ The delayed presentation of retinal detachment may have resulted from a post-operative PVD developing after anterior vitrectomy in 2 cases (8-18 weeks after scleral-sutured PCIOL surgery), and from temporary post-operative tamponade due to intraocular gas and suprachoroidal effusions in another patient who underwent PPV more than 6 weeks previously. In other cases the delayed presentation may have related to the small retinal break size, or to delayed retinal break formation secondary to static vitreous traction associated with vitreous incarceration. The variable intervals to presentation with retinal detachment underline the need for regular dilated fundus examination during follow-up.

There exists the possibility that the retinal tears and detachments were unrelated to scleral-sutured PCIOL surgery, given the other risks factors for retinal detachment present in these patients. Indeed, this may be the case with patient 5 , who developed an operculated tear and detachment that perhaps resulted from the scleral-sutured PCIOL surgery, or from the ensuing events including post-operative endophthalmitis and intravitreal antibiotics. However, the chronological sequence whereby retinal tears or detachments occurred within 8 weeks of scleral-sutured PCIOL surgery, the observation of retinal tears developing during such surgery, and the findings of retinal tears attached to vitreous incarcerated in the suture tracts renders a coincidence unlikely in the remaining cases.

Retinal detachment associated with scleral-sutured PCIOLs should be assessed for the presence of anterior retinal breaks associated with bridging vitreous strands within 2 clock-hours of the sutures and entry-sites. Pneumatic retinopexy, scleral buckling or vitrectomy may be employed as indicated by the nature of the vitreoretinal relationships, size and position of the break(s) and the patient's ability to posture. Although the optimal treatment modality for such retinal detachment is not known, a vitrectomy-gas procedure most commonly addressed these issues.

The vitreoretinal complications of scleral-sutured PCIOLs relate mostly to the disturbance of vitreous, rather than to direct retinal impact. Perioperative observations implicate the intraocular suture, pars plana entry-sites and PVD in the pathogenesis of peripheral retinal tears. Prophylaxis against retinal detachment would require confluent retinopexy to the entire anterior retina within 2 clock-hours of the suture and entry-sites, although such empirical treatment with its attendant risk of proliferative vitreo-retinopathy (PVR) is not justified if breaks are not evident during a careful intraoperative search. The small sample size and incomplete data recording in the uncomplicated group prevented a more detailed analysis of such factors as pre-existing PVD, anterior to pars plana vitrectomy technique, suturing technique and the issue of prophylaxis. A prospective study could address these issues and might provide conclusions regarding the choice of surgical techniques in different subgroups of patients requiring scleral-sutured surgery. Nevertheless, careful attention to the posterior hyaloid face, basal gel, surgical entry-sites and suturing technique, and regular dilated retinal examination during follow-up are recommended to decrease post-operative vitreoretinal sequelae.

R.D.B. is funded by the Sutor Research Fellowship, Moorfields Eye Hospital.

Key words: Retinal detachment, Sutured posterior chamber intraocular lens. 


\section{REFERENCES}

1. Apple DJ, Mamalis N, Loftfield K, Googe JM, Novak LC, Kavka-van Norman D, et al. Complication of intraocular lenses: a historical and histopathological review. Surv Ophthalmol 1984;29:1-54.

2. Kraff MC, Sanders DR, Lieberman HL. Monitoring for continuing endothelial cell loss with cataract extraction and intraocular lens implantation. Ophthalmology 1982;89:30-4.

3. Sugar A, Meyer RF, Heidermann, D, Kaplan S, Berka T, Maguire K, Martonyi C. Specular microscopic follow-up of corneal grafts for pseudophakic bullous keratopathy. Ophthalmology 1985;92:325-30.

4. Girard LJ. Pars plana phacoprosthesis (aphakic intraocular implant): a preliminary report. Ophthalmic Surg 1981;12:19-21.

5. Girard LJ, Nino N, Wesson M, Maghraby A. Scleral fixation of a subluxated posterior chamber intraocular lens. J Cataract Refract Surg 1988;14:326-7.

6. Lewis JS. Ab externo sulcus fixation. Ophthalmic Surg 1991;22:692-5.

7. Heidemann DG, Dunn SP. Transsclerally sutured intraocular lenses in penetrating keratoplasty. Am J Ophthalmol 1992;113:619-25.

8. Hill JC. Transsclerally-fixated posterior chamber intraocular implants without capsular support in penetrating keratoplasty. Ophthalmic Surg 1992;23: 320-4.

9. Kora Y, Fukado Y, Yaguchi S. Sulcus fixation of posterior chamber lenses by transscleral sutures. J Cataract Refract Surg 1991;17:636-9.

10. Horiguchi M, Hirose H, Koura T, Satou M. Identifying the ciliary sulcus for suturing a posterior chamber intraocular lens by transillumination. Arch Ophthalmol 1993;111:1693-5.

11. Cowden JW, Hu BV. A new surgical technique for posterior chamber lens fixation during penetrating keratoplasty in the absence of capsular or zonular support. Cornea 1988;7:231-5.

12. Duffey RJ, Holland EJ, Agapitos PJ, Lindstrom RL. Anatomic study of transsclerally sutured intraocular lens implantation. Am J Ophthalmol 1989;108:300-9.

13. Agapitos PJ, Lindstrom RL. Transscleral ciliary sulcus fixation of posterior chamber intraocular lens implants. Aust NZ J Ophthalmol 1989;17:169-72.

14. Hu BV, Shin DH, Gibbs KA, Hong YJ. Implantation of posterior chamber lens in the absence of capsular and zonular support. Arch Ophthalmol 1988;106: 416-20.

15. Fanous M, Friedman S. Ciliary sulcus fixation of a dislocated posterior chamber intraocular lens using liquid perfluorophenanthrene. Ophthalmic Surg 1992; 23:551-2.

16. Anand R, Brown R. Simplified technique for suturing dislocated posterior chamber intraocular lens to the ciliary sulcus [letter]. Arch Ophthalmol 1990;108: 1205-6.

17. Nabors G, Varley M, Charles S. Ciliary sulcus fixation of a dislocated posterior chamber intraocular lens. Ophthalmic Surg 1990;21:263-5.

18. Maquire A, Blumenkranz M, Ward T, Winkelman J. Scleral loop fixation for posteriorly dislocated intraocular lenses: operative techniques and long-term results. Arch Ophthalmol 1991;109:1754-8.
19. Smiddy W. Dislocated posterior chamber intraocular lens: a new technique of management. Arch Ophthalmol 1989;107:1678-80.

20. Campo R, Chunk K, Oyakawa R. Pars plana vitrectomy in the management of dislocated posterior chamber lenses. Am J Ophthalmol 1989;108:529-34.

21. Murray T, Abrams G, Stanley J. Pars plana vitrectomy in the management of dislocated posterior chamber lenses [letter]. Am J Ophthalmol 1990;109:362.

22. Lewis H, Sanchez G. The use of perfluorocarbon liquids in the repositioning of posteriorly dislocated intraocular lenses. Ophthalmology 1993;100:1055-9.

23. Soong HK, Musch DC, Kowal V, Sugar A, Meyer RF. Implantation of posterior lenses in the absence of lens capsule during penetrating keratoplasty. Arch Ophthalmol 1989;107:660-5.

24. Sundmacher R, Althaus C, Wester R. Experience with transscleral fixation of posterior chamber lenses. Graefes Arch Clin Exp Ophthalmol 1991;229:512-6.

25. McCluskey P, Harrisberg B. Long-term results using scleral-fixated posterior chamber intraocular lenses. J Cataract Refract Surg 1994;20:34-9.

26. Price FW, Whitson WE. Visual results of suture-fixated posterior chamber lenses during penetrating keratoplasty. Ophthalmology 1989;96:1234-40.

27. Faulborn J, Conway BP, Machemer R. Surgical complications of pars plana vitreous surgery. Ophthalmology 1978;85:116-25.

28. Oyakawa RT, Schachat AP, Michels RG, Rice TA. Complications of vitreous surgery for diabetic retinopathy. I. Intraoperative complications. Ophthalmology 1983;90:517-21.

29. Foos RY. Posterior vitreous detachment. Trans Am Acad Ophthalmol Otolaryngol 1972;76:480-97.

30. McLeod D. Giant retinal tears after central vitrectomy. Br J Ophthalmol 1985;69:96-8.

31. Javitt JC, Street DA, Tielsch JM, Wang Q, Kolb M, et al. National outcomes of cataract extraction: retinal detachment and endophthalmitis after out-patient cataract surgery. Ophthalmology 1994;101:100-6.

32. Lyle WA, Jin JC. Secondary intraocular lens implantation: anterior chamber vs posterior chamber lenses. Ophthalmic Surg 1993;24:375-81.

33. Sinskey RM, Amin P, Stoppel JO. Indications for and results of a large series of intraocular lens exchanges. J Cataract Refract Surg 1993;19:68-71.

34. Haimann MH, Burton TC, Brown CK. Epidemiology of retinal detachment. Arch Ophthalmol 1982;100: 289-92.

35. Davis MD, Segal PP, McCormick A. The natural course followed by the fellow eye in patients with rhegmatogenous retinal detachment. In: Pruett RC, Regan CD, editors. Retina congress. New York: Appleton-Century-Crofts, 1974:643.

36. Takahashi M, Jalkh A, Hoskins J, Trempe CL, Schepens CL. Biomicroscopic evaluation and photography of liquefied vitreous in some vitreoretinal disorders. Arch Ophthalmol 1981;99:1555-9.

37. Nielsen NE, Naeser K. Epidemiology of retinal detachment following extracapsular cataract extraction: a follow-up study with an analysis of risk factors. J Cataract Refract Surg 1993;19:675-80.

38. Michels RG, Wilkinson CP, Rice TA. Retinal detachment. St Louis: CV Mosby,1990:715. 